\section{Rowcovers and Plant Architecture Influence Development and Spatial Distribution of Bell Pepper Fruit}

\author{
M.M. Gaye', G.W. Eaton, and P.A. Joliffe \\ Department of Plant Science, The University of British Columbia, \\ Vancouver, British Columbia V6T 1Z4, Canada
}

Additional index words. bell peppers, Capsicum annuum, fruiting patterns, demography, yield

\begin{abstract}
The effects of rowcovers and plant architecture on fruit development and spatial distribution were assessed in a study of field-grown bell peppers (Capsicum annuum L. cv. Ace Hybrid). A forced regression procedure indicated that rowcovers advanced anthesis and delayed harvest dates on the lower nodes and increased the duration of maturation (over all branches and nodes). Rowcovers did not influence total fruit yield. Fruit were obtained from as many as nine node locations, but the largest portion of the total yield was obtained from the first five nodes. Fruit frequency declined with later nodes and lateral branches, compared with the main branch. Fruit produced after lateral branch four on uncovered plants were below an acceptable market size. Marketable fruit were obtained from all nodes, with the exception of node six of covered plants.
\end{abstract}

Rowcovers have been used successfully to promote early plant development and increase yields (Gerber et al., 1985; Wells and Loy, 1985). Their use enables commercial production of many warm-season crops in locations that are otherwise climatically marginal for their culture. For example, studies conducted in south coastal British Columbia have shown that rowcovers applied over bell peppers promote early fruiting and enhance total fruit yield (Maurer and Frey, 1987).

Structures within a plant may have a differential response to environmental influences such as increased plant competition (Mauk et al., 1983) and temperature (Stobbe et al., 1966). An accurate description of fruiting patterns of bell peppers could benefit plant breeders and enable judicious management decisions. This study was initiated to describe fruit distribution on field-grown bell peppers and determine the effects of rowcovers and plant architecture on fruiting patterns and yield.

Received for publication 5 Apr. 1991. Accepted for publication 9 Dec. 1991. Financial support was provided by an Agri-Food Regional Development Subsidiary Agreement grant awarded to A.R. Maurer, Agriculture Canada, and Natural Sciences and Engineering Research Council of Canada operating grants awarded to P.A.J. and G.W.E. We thank A.R. Maurer for his interest in the conduct of this study, and M.M. Henderson of publishing this paper was defrayed in part by the payment of page charges. Under postal regulations, this paper therefore must be hereby marked advertisement solely to indicate this fact.

'Current address: Cloverdale Soil Conservation Group, 17720 - 57th Ave., Surrey, British Columbia, V3S 4P9, Canada. and F.M. Seywerd for technical support. The cost
The study was conducted in 1988 at the Agriculture Canada Research Station, Agassiz, British Columbia. Seven-week-old 'Ace Hybrid' bell pepper plants were transplanted on 12 May into 1.1.m-wide raised beds mulched with black polyethylene. The seedlings were planted in twin rows, $0.5 \mathrm{~m}$ apart, at a within-row spacing of $0.40 \mathrm{~m}$. The sandy loam soil (Eutrochrept) was prepared with a broadcast application of $165 \mathrm{~N}-165 \mathrm{P}-165 \mathrm{~K}$ and $4.5 \mathrm{~B}$ (all kg.ha ${ }^{-1}$ ) and with $23 \mathrm{t}$ cattle manure/ha. Plots were not covered or were covered with slit polyethylene tunnels until 7 July. The design was a randomized complete block with four blocks. In each plot, four plants were randomly selected from 10 plants for sampling.

Flowers were marked at anthesis with small labels attached to the peduncle with string, beginning at first flowering and continuing to 12 Aug. The date of anthesis was recorded on each label. Labelled fruit were harvested at the mature green stage, twice weekly, until 21 Sept. The branch type, and branch and node location of the fruit were recorded at harvest. The main branch (branch 0) was the primary division of the main stem, usually occurring after the eighth main-stem node (Fig. 1). Lateral or side branches developing on the main stem below the primary division were numbered acropetally according to the main-stem node from which they developed. The nodes on each branch were numbered acropetally from the main stem.

Data were analyzed for treatment effects after orthogonalization (Winer, 1971), in which independent variables were forced at

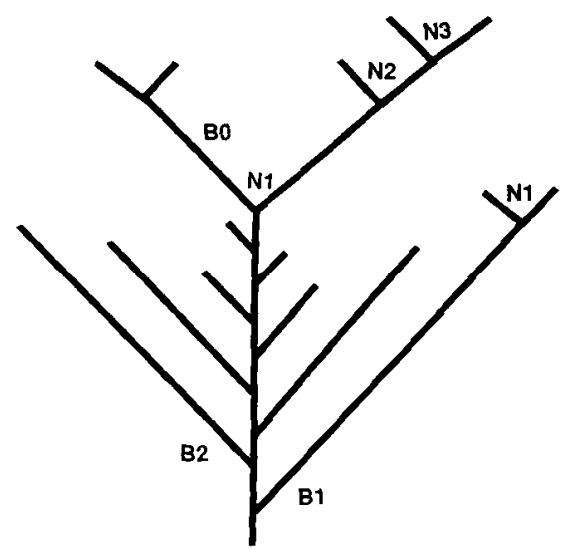

Fig. 1. Node and branch numbering system for bell pepper plants. $\mathrm{N}$ and $\mathrm{B}$ denote node and branch, respectively.
Table 1. Increments in $R^{2}$ (percent) for bell pepper fruit development and yield as influenced by rowcovers and plant architecture.

\begin{tabular}{|c|c|c|c|c|c|c|c|}
\hline $\begin{array}{l}\text { Source of } \\
\text { variation }\end{array}$ & df & $\begin{array}{c}\text { Anthesis } \\
\text { date }^{2}\end{array}$ & $\begin{array}{c}\begin{array}{c}\text { Harvest } \\
\text { date }\end{array} \\
\end{array}$ & $\begin{array}{c}\text { No. days } \\
\text { to } \\
\text { maturity }\end{array}$ & $\begin{array}{c}\text { Total fruit } \\
\text { yield/plant }\end{array}$ & $\begin{array}{c}\text { No. } \\
\text { fruit/plant }\end{array}$ & $\begin{array}{c}\text { Fruit } \\
\text { size }\end{array}$ \\
\hline Total $R^{2}$ & 67 & 100 & 100 & 100 & 100 & 100 & 100 \\
\hline Rowcover (C) & 1 & 5 & 1 & $7^{* *}$ & 0 & 0 & 4 \\
\hline Branch type (BT) & 1 & $16^{* *}$ & 9* & 3 & $33^{* *}$ & $36^{*}$ & 0 \\
\hline $\mathrm{C} \times \mathrm{BT}$ & 1 & 0 & 0 & 0 & 1 & 0 & 1 \\
\hline \multicolumn{8}{|c|}{ Branch location (BL) } \\
\hline Linear (l) & 1 & $8^{*}$ & 0 & $14^{* *}$ & 2 & 1 & $32^{* *}$ \\
\hline Quadratic (q) & 1 & 0 & 0 & 0 & 0 & 0 & 2 \\
\hline $\mathrm{C} \times \mathrm{BL}_{1}$ & 1 & 2 & 4 & 1 & 0 & 0 & $8^{* *}$ \\
\hline $\mathrm{C} \times \mathrm{BL}_{\mathrm{q}}$ & 1 & 1 & 2 & 1 & 0 & 0 & 2 \\
\hline \multicolumn{8}{|l|}{ Node location (N) } \\
\hline Linear & 1 & $62^{* *}$ & $58^{* *}$ & 0 & $10^{* *}$ & $10^{* *}$ & 0 \\
\hline Quadratic & 1 & 0 & 0 & 0 & $5^{*}$ & $5^{*}$ & $5^{*}$ \\
\hline $\mathrm{C} \times \mathrm{N}_{1}$ & 1 & $2^{* *}$ & $2^{*}$ & 0 & 0 & 0 & 0 \\
\hline $\mathrm{C} \times \mathrm{N}_{\mathrm{q}}$ & 1 & 0 & 0 & 0 & 0 & 0 & 0 \\
\hline $\mathrm{C} \times \mathrm{BT} \times \mathrm{N}_{1}$ & 1 & 0 & 1 & 2 & 0 & 0 & 0 \\
\hline Residual & 55 & 4 & 23 & 72 & 49 & 48 & 46 \\
\hline
\end{tabular}

zTotal sums of squares for fruit development and yield parameters (left to right) were 10, 636; 11, 680; 3,$643 ; 138 ; 12,175$; and 47,167 , respectively.

$*, * *$ Significant at $P=0.05$ and 0.01 , respectively. 
Table 2. Fruit yield (in grams) per bell pepper plant as influenced by rowcovers, branch type, branch location, and node number.

\begin{tabular}{|c|c|c|c|c|c|c|c|c|c|c|c|}
\hline \multirow[b]{2}{*}{ Rowcover } & \multirow[b]{2}{*}{ Branch ${ }^{2}$} & \multicolumn{9}{|c|}{ Node } & \multirow[b]{2}{*}{ Sum } \\
\hline & & 1 & 2 & 3 & 4 & 5 & 6 & 7 & 8 & 9 & \\
\hline \multirow[t]{10}{*}{ No covers } & 1 & 139 & 103 & 126 & 30 & -- & 7 & 7 & --- & $\cdots$ & 412 \\
\hline & 2 & 96 & 84 & 54 & 37. & 6 & 8 & --- & ... & --- & 285 \\
\hline & 3 & 50 & 52 & 6 & -- & -.- & --. & -.. & --- & $\cdots$ & 108 \\
\hline & 4 & 74 & 65 & 7 & -- & --- & --- & -. & --. & $\cdots$ & 146 \\
\hline & 5 & 17 & 32 & 6 & --- & $\ldots$ & - & -- & ... & --- & 55 \\
\hline & 6 & 25 & 13 & -.. & -- & -- &.- & ..- & --- & -.. & 38 \\
\hline & 7 & 2 & 4 & -.- & -- & $\ldots$ & --- & --- & ... & --- & 5 \\
\hline & 8 & 1 & ... &.- & $\cdots$ & --- & $\cdots$ & - & $\ldots$ & --- & 1 \\
\hline & Main & 64 & 166 & 492 & 181 & 74 & -- & $\cdots$ & --- & $\cdots$ & 977 \\
\hline & Side & 404 & 352 & 200 & 66 & 6 & 15 & 7 & $\ldots$ & $\cdots$ & 1050 \\
\hline \multirow[t]{10}{*}{ Rowcovers } & 1 & 74 & 69 & 50 & 53 & 20 & - & -- & -- & -- & 266 \\
\hline & 2 & 100 & 92 & 29 & 64 & 26 & 4 & 7 & ... & --- & 324 \\
\hline & 3 & 75 & 68 & 27 & 15 & ... & 7 & 6 & $\ldots$ & -- & 197 \\
\hline & 4 & 68 & 56 & 13 & 15 & 6 & --- & $\cdots$ & --- & --- & 159 \\
\hline & 5 & 65 & 27 & -- & --- & $\cdots$ & $\cdots$ & $\ldots$ & -- & $\cdots$ & 92 \\
\hline & 6 & 43 & 8 & -.. & --- & ... & --- & $\ldots$ & --- & -- & 51 \\
\hline & 7 & 43 & -.- & - & -.- & ..- & -. & --- & -.- & -- & 43 \\
\hline & 8 & 17 & --- & ... & --- & ... & --- & ... & $\cdots$ & -- & 17 \\
\hline & Main & 75 & 121 & 284 & 450 & 237 & 20 & 26 & 18 & 8 & 1238 \\
\hline & Side & 486 & 320 & 119 & 147 & 52 & 11 & 13 & --- & $\ldots$ & 1149 \\
\hline
\end{tabular}

${ }^{2}$ Branches 1-8 are side branches and are numbered acropetally; main is the branch developing after the primary division of the main stem.

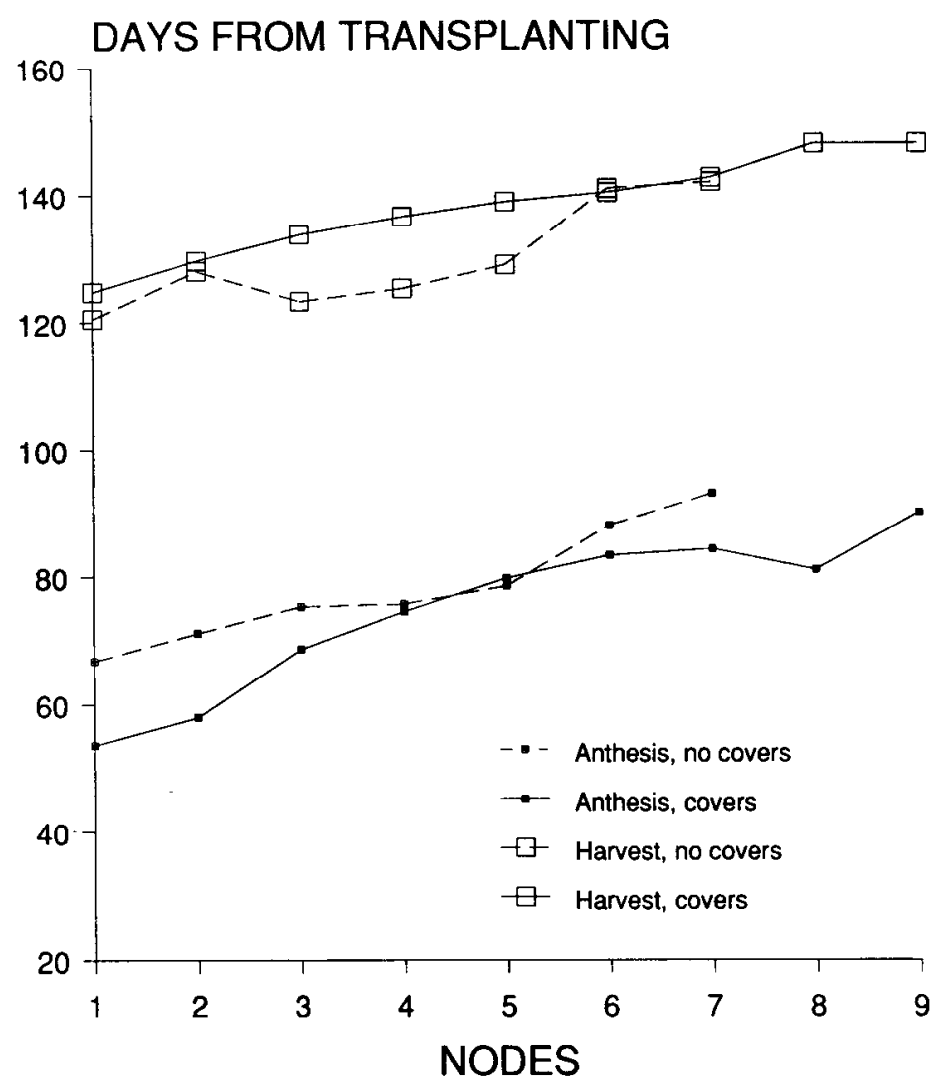

Fig. 2. The influence of rowcovers and node location on anthesis and harvest dates of bell peppers.

each successive step into the regression in a predetermined sequence. Data were classified according to rowcover treatment, branch type (main or side), branch location, and node location, and each category was treated as an independent variable. Nodes located on main and side branches were combined for analysis. Rowcover was entered first into the regression to best assess its effect on the dependent variable. The remaining indepen- dent variables were entered in an assumed hierarchical order, giving increments in $R^{2}$ resulting from the addition of each independent variable. Such increments correspond to those of orthogonalized independent variables. The sequence was the same for each dependent variable. Dependent variables were anthesis and harvest date, maturation days, fruit size, fruit frequency, and total fruit yield. Treatment effects were examined on means of four blocks. In each case, the dependent variable was regressed directly against the first independent variable entered into the regression, while subsequent components were calculated as residuals from a multiple regression on the previously entered components. Analysis of variance was then conducted on the residuals.

Node location was the greatest significant contributor to variation in anthesis and harvest dates $(62 \%$ and $58 \%$ incremental increase in $R^{2}$, respectively), followed by branch type (16\% and $9 \%$ increase, respectively) (Table 1). Flowering and fruit harvest were earlier at the lower node numbers (Fig. 2) and on the main branch than on the side branches. The mean number of days from transplanting to anthesis was 62 and 70 days for the main and side branches, respectively. Fruit from the main branch was harvested 119 days after transplanting compared with 126 days from the side branches. The addition of the interaction rowcovers and the linear effect of node location to the regressions accounted for a $2 \%$ increase in $R^{2}$ (Table 1 ). Rowcovers generally advanced flower opening and delayed harvest (Fig. 2). The linear effect of branch location was a significant contributor to variation in anthesis date but not to harvest date. Rowcovers and branch location were significant contributors to variation in days to maturation (7\% and $14 \%$ increase in $R^{2}$, respectively). The mean number of days to maturity significantly increased with the use of rowcovers (53 and 57 days for uncovered and covered treatments, respectively) and generally increased with later-developing branches.

Total fruit yield and number of fruit per plant were influenced by branch type and node location but not by the use of rowcovers (Table 1). Branch type accounted for an increase of more than $30 \%$ in $R^{2}$, and node location (linear and quadratic trends) accounted for a $15 \%$ increase in regressions of fruit frequency and yield. Nodes 1 to 5 accounted for $98 \%$ of the fruit produced on the main and side branches (Table 2, Fig. 3). Nodes 3 and 4 accounted for $64 \%$ of total main branch fruit, and nodes 1 and 2 for $71 \%$ of fruit from the side branches. Fruit frequency followed a similar trend. Nodes 1 and 2 of the side branches produced the most fruit (mean value 3.7 fruit) followed by nodes 3 and 4 of the main branch (mean 3.4 fruit). The mean number of fruit per node was less than one after node 5 . These results reflect the sequential nature of plant development: the initial development of the main branch followed by the acropetal development of lateral branches from the main stem. Eight lateral branches may develop from the main stem; hence, side branches have the potential to develop more nodes 1 and 2 than the main branch.

Branch location was the greatest contributor to variation in individual fruit weight and resulted in a 33\% incremental increase in $R^{2}$ (Table 1). Fruit size decreased more with higher branches of uncovered plants than covered plants (Table 3). Most fruit produced after branch 4 in uncovered plants did 
Table 3. Fruit size (in grams) of bell peppers as influenced by rowcovers, and branch and node location.

\begin{tabular}{|c|c|c|c|c|c|c|c|c|c|c|}
\hline \multirow[b]{2}{*}{ Rowcover } & \multirow[b]{2}{*}{ Branch $^{2}$} & \multicolumn{9}{|c|}{ Node } \\
\hline & & 1 & 2 & 3 & 4 & 5 & 6 & 7 & 8 & 9 \\
\hline \multirow[t]{9}{*}{ No covers } & 1 & 131 & 117 & 135 & 159 & --- & 106 & 105 & $\cdots$ & -- \\
\hline & 2 & 128 & 96 & 123 & 117 & 88 & 133 & -.. & -- & -. \\
\hline & 3 & 115 & 104 & 97 & -.- & -.. & ... & .-. & ... & -- \\
\hline & 4 & 118 & 116 & 117 & ... & ... & ... & ... & -.- & ... \\
\hline & 5 & 55 & 72 & 96 & --- & -.. & --- & .-. & $\ldots$ & -- \\
\hline & 6 & 79 & 103 & - & --- & -- & -.- & $\ldots$ & --. & -. \\
\hline & 7 & 24 & 62 & --- & ... & --- & $\ldots$ & ... & --- & ... \\
\hline & 8 & 16 & -.- & --- & $\ldots$ & -- & $\cdots$ & -.. & -- & $\cdots$ \\
\hline & 0 & 102 & 99 & 119 & 91 & 108 & -- & -.. & --- & $\cdots$ \\
\hline \multirow[t]{9}{*}{ Rowcovers } & 1 & 84 & 111 & 133 & 140 & 109 & $\cdots$ & --- & $\cdots$ & -- \\
\hline & 2 & 124 & 134 & 156 & 171 & 140 & 70 & 113 & --- & -. \\
\hline & 3 & 100 & 109 & 106 & 122 & -- & 108 & 96 & $\cdots$ & $\cdots$ \\
\hline & 4 & 91 & 112 & 108 & 124 & 91 & -.- & $\ldots$ & --- & - \\
\hline & 5 & 95 & 144 & --- & -.- & $\cdots$ & -.. & $\ldots$ & --- & -- \\
\hline & 6 & 76 & 129 & --- & ..- & ... & --- & $\ldots$ & --. & --- \\
\hline & 7 & 99 & --. & $\cdots$ & --- & -.- & $\cdots$ & $\cdots$ & $\cdots$ & $\cdots$ \\
\hline & 8 & 93 & $\ldots$ & --- & -.- & --- & --. & $\cdots$ & --- & --- \\
\hline & 0 & 133 & 88 & 101 & 100 & 102 & 107 & 105 & 96 & 124 \\
\hline
\end{tabular}

${ }^{2}$ Branches 1-8 are side branches and are numbered acropetally; branch 0 is the main shoot developing after the primary division of the main stem.

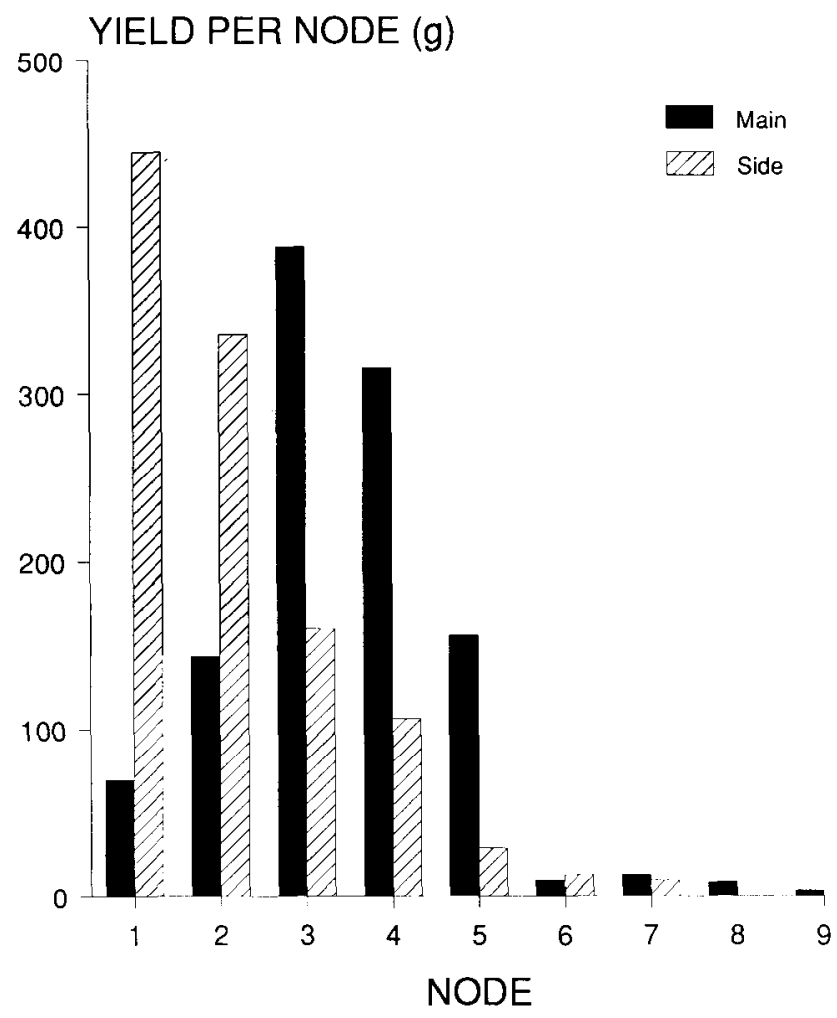

Fig. 3. Distribution of plant yield by node location and branch type of bell pepper. Main refers to main branch, and side to side branches developing from main stem.

not reach a marketable size under our climatic conditions, whereas covered plants produced marketable fruit at all branches, with the exception of branch 6 .

Rowcovers delayed harvest and did not influence total fruit yield per plant. Other covered plants may have shaded developing fruit and extended the maturation period. Also, increased vegetative development, and hence greater capacity to produce assimilates, may have enabled fruit produced on late-developing branches of covered plants to reach a marketable size. Lovett Doust and Eaton (1982) noted the possible association of enhanced foliage production and increased fruit production in a study of Phaseolus vulgaris $\mathrm{L}$.

Reproductive yield was partitioned among fruit produced on as many as nine nodes; however, the greatest portion of the total yield was obtained from nodes 1 to 5 . Fruit production on nodes above 5 may be restricted by late-season climatic conditions in south coastal British Columbia. Commercial harvesting after node five may not be profitable because of low fruit frequency. Further, pruning or flower removal may reduce competition for assimilates and light, thereby improving fruit size or ripening period.

Previous studies concerning the influence of rowcovers on bell peppers have concentrated on the yield response (Brown et al., 1987; Stobbe et al., 1966). This study has described fruiting patterns and assessed the influence of rowcovers and plant architecture on fruit maturation and yield. Our results may be relevant in cultural management decision or in bell pepper breeding programs.

\section{Literature Cited}

Brown, J.D., C. Stevens, M.C. Osborn, and H.M. Bryce. 1987. Use of row covers and black plastic mulch in control of southern blight on production of bell peppers. Proc. Natl. Agr. Plastics Congr. 20:46-52.

Gerber, J.M., J.E. Brown, and W.E. Splittstoesser. 1983. Economic evaluation of plastic mulch and row tunnels for use in muskmelon production. Proc. Natl. Agr. Plastics Congr. 17:4650.

Lovett Doust, J. and G.W. Eaton. 1982. Demographic aspects of flower and fruit production in bean plants, Phaseolus vulgaris L. Amer. J. Bot. 69:1156-1164.

Mauk, C.S., P.J. Breen, and H.J. Mack. 1983. Yield response of major pod-bearing nodes in bush snap beans to irrigation and plant population. J. Amer. Soc. Hort. Sci. 108:935-939.

Maurer, A.R. and B.M. Frey. 1987. Response of bell peppers to row covers. Agriculture Canada. Agassiz Res. Sta. Tech. Rpt. 31.

Stobbe, E.H., D.P. Ormrod, and C.J. Woolley. 1966. Blossoming and fruit set patterns in Phaseolus vulgaris L. as influenced by temperature. Can. J. Bot. 44:813-819.

Rylski, I. 1986. Improvement of pepper fruit quality and timing of harvest by shading under high solar radiation conditions. Acta Hort. 191:221228.

Wells, O.S. and J.B. Loy. 1985. Intensive vegetable production with rowcovers. HortScience 20:822-826.

Winer, B.J. 1971. Statistical principals in experimental design. 2nd ed. McGraw-Hill, New York. 